\title{
Heterologous Expression of Septoria lycopersici Tomatinase in Cladosporium fulvum: Effects on Compatible and Incompatible Interactions with Tomato Seedlings
}

\author{
Rachel E. Melton, ${ }^{1}$ Lynda M. Flegg, ${ }^{2}$ James K. M. Brown, ${ }^{3}$ Richard P. Oliver, ${ }^{4}$ Michael J. Daniels, ${ }^{1}$ and \\ Anne E. Osbourn ${ }^{1}$ \\ ${ }^{1}$ Sainsbury Laboratory, ${ }^{2}$ University of East Anglia, ${ }^{3} \mathrm{~J} o h n$ Innes Centre, Norwich, UK; ${ }^{4}$ Carlsberg Laboratory, \\ Copenhagen, Denmark \\ Accepted 30 November 1997.
}

The anti-fungal, steroidal, glycoalkaloid saponin, $\alpha$ tomatine, is present in uninfected tomato plants in substantial concentrations, and may contribute to the protection of tomato plants against attack by phytopathogenic fungi. In general, successful fungal pathogens of tomato are more resistant to $\alpha$-tomatine in vitro than fungi that do not infect this plant. For a number of tomato pathogens, this resistance has been associated with the ability to detoxify $\alpha$-tomatine through the action of enzymes known as tomatinases. In contrast, the biotrophic tomato pathogen Cladosporium fulvum is sensitive to $\alpha$-tomatine and is unable to detoxify this saponin. This paper describes the effects of heterologous expression of the cDNA encoding tomatinase from the necrotroph Septoria lycopersici in two different physiological races of $C$. fulvum. Tomatinaseproducing $C$. fulvum transformants showed increased sporulation on cotyledons of susceptible tomato lines. They also caused more extensive infection of seedlings of resistant tomato lines. Thus, $\alpha$-tomatine may contribute to the ability of tomato to restrict the growth of $C$. fulvum in both compatible and incompatible interactions.

$\alpha$-Tomatine is a steroidal glycoalkaloid that is found in tomato (Lycopersicon esculentum) and that belongs to the group of plant secondary metabolites known as saponins (Roddick 1974). Like many other saponins, $\alpha$-tomatine has potent antifungal properties, and consequently it has been suggested that this compound may represent a preformed chemical barrier that protects tomato plants against attack by phytopathogenic fungi (for reviews see Osbourn 1996a, 1996b). In general, fungal pathogens of tomato are more resistant to $\alpha$-tomatine in vitro than are fungi that do not infect this plant (Arneson and Durbin 1968a; Schlösser 1975; Steel and Drysdale 1988; Suleman et al. 1996).

The primary mechanism of toxicity of $\alpha$-tomatine to fungi is probably due to its ability to complex with sterols in fungal membranes, resulting in loss of membrane integrity (Schulz and Sander 1957; Roddick and Drysdale 1984; Steel and

Corresponding author: Anne E. Osbourn; E-mail: osbourna@bbsrc.ac.uk
Drysdale 1988; Keukens et al. 1995). Thus, for some fungi, the ability to colonize tomato tissue may be due to intrinsic resistance to $\alpha$-tomatine at the membrane level (Arneson and Durbin 1968b; Schlösser 1972; Steel and Drysdale 1988). Sterol-deficient mutants of a tomato-attacking isolate of Fusarium solani have provided good evidence that membrane composition can be important in determining the ability of fungi to infect tomato (Défago and Kern 1983; Défago et al. 1983). These mutants showed increased resistance to $\alpha$ tomatine and were able to infect green tomato fruits, which contained over 20 times more $\alpha$-tomatine than the red fruits. The wild-type $F$. solani isolate was pathogenic only to ripe tomato fruits.

Other fungal pathogens of tomato actively detoxify $\alpha$ tomatine by the production of specific enzymes known as tomatinases (reviewed by Osbourn 1996a, 1996b). These enzymes act in various ways to hydrolyze sugar molecules from the tetrasaccharide group attached to the C-3 carbon of $\alpha$ tomatine. The deglycosylated products are less inhibitory to fungal growth, suggesting that $\alpha$-tomatine degradation may be an important strategy for successful infection of tomato plants. The contribution of tomatinases to fungal pathogenicity has not yet been tested genetically, although recent progress in the characterization of these enzymes and the isolation of the genes that encode them should allow the generation of specific tomatinase-minus mutants by targeted gene disruption (Osbourn et al. 1995; Sandrock et al. 1995; Lairini et al. 1996). Experiments of this nature involving the oat root pathogen Gaeumannomyces graminis var. avenae, which detoxifies the triterpenoid saponin avenacin A-1, have already established that saponin detoxification is essential for the interaction between G. graminis var. avenae and oats (Bowyer et al. 1995).

The "gene-for-gene" interaction between distinct physiologic races of the biotrophic tomato pathogen Cladosporium fulvum and near-isogenic tomato lines carrying different resistance $(C f)$ genes is well documented (De Wit 1992). During infection of susceptible tomato lines, C. fulvum grows in the intercellular spaces of tomato leaves and causes very little damage to its host until the final stages of infection (Lazarovitz and Higgins 1976; De Wit 1977; Hammond- 
Kosack and Jones 1994). During incompatible interactions, localized host resistance responses occur that restrict pathogen ingress shortly after penetration of a stomatal opening. Induced responses include mesophyll cell enlargement, callose and lignin deposition, and sometimes cell death (Lazarovitz and Higgins 1976; De Wit 1977; Hammond-Kosack and Jones 1994). The polyacetylenic phytoalexins, falcarindiol and falcarinol, accumulate in tomato leaf tissue in response to infection with virulent or avirulent races of $C$. fulvum, with more rapid accumulation occurring in incompatible interactions (De Wit and Flach 1979; De Wit and Kodde 1981; Batista and Higgins 1990).

In an early study of the effects of $\alpha$-tomatine on $C$. fulvum, Van Dijkman and Kaars-Sijpesteijn (1971) reported that the saponin had little effect on spore germination and mycelial growth in liquid culture. However, Dow and Callow (1978) subsequently showed that under low nutrient conditions, and at $\mathrm{pHs}$ optimal for $\alpha$-tomatine toxicity, germ tube extension was inhibited by concentrations as low as 8 to $120 \mu \mathrm{M}$, with irreversible damage at $150 \mu \mathrm{M}$. The concentration of $\alpha$ tomatine in uninfected tomato leaves has been estimated to be as high as $1 \mathrm{mM}$, assuming uniform distribution (Arneson and Durbin 1968a). Therefore, $\alpha$-tomatine may be anticipated to have some effect on the growth of $C$. fulvum in planta. However, it is not clear how the saponin is distributed and compartmentalized within the leaf tissue, and hence whether $C$. fulvum is likely to encounter antifungal levels of $\alpha$-tomatine during growth in the intercellular leaf spaces. The local $\mathrm{pH}$ at the infection site may also be important in modulating the effects of $\alpha$-tomatine, since the antifungal activity of the saponin is greatest when it is in its unprotonated form $(\mathrm{pH}>$ 7) (Arneson and Durbin 1968a; Dow and Callow 1978; Roddick and Drysdale 1984). Indeed, it has been suggested that one mechanism by which pathogens may counter the effects of $\alpha$-tomatine may involve reduction of the $\mathrm{pH}$ at the infection site to levels at which the saponin is no longer toxic (Schlösser 1975; Schönbeck and Schlösser 1976; Roddick and Drysdale 1984).

The experiments described here were designed to test whether $\alpha$-tomatine is likely to restrict the growth of $C$. fulvum during infection of susceptible or resistant tomato lines. C. fulvum is apparently unable to degrade $\alpha$-tomatine (see below), while the necrotrophic tomato pathogen Septoria lycopersici produces an extracellular tomatinase enzyme that detoxifies $\alpha$-tomatine by the removal of a single terminal Dglucose molecule from the tetrasaccharide moiety of the saponin (Arneson and Durbin 1967, 1968b). Transformants of two different races of $C$. fulvum expressing the cDNA encoding the $S$. lycopersici tomatinase enzyme were generated, and the effects of tomatinase expression on $C$. fulvum/tomato interactions are described. In preliminary experiments with mature plants of susceptible tomato lines the tomatinaseproducing transformants appeared to be more pathogenic than control strains. In the experiments described here, cotyledons were used in preference to adult plants because they afforded a more reliable and reproducible system for infection, and could readily be subjected to microscopic analysis. Other studies have demonstrated the validity of cotyledons in analysis of interactions between C. fulvum and tomato (HammondKosack and Jones 1994; Hammond-Kosack et al. 1996; May et al. 1996).

\section{RESULTS}

\section{Expression of tomatinase activity by $C$. fulvum transformants.}

The vector pAN52-1/TOM was constructed for heterologous expression of tomatinase in C. fulvum by ligation of a cDNA fragment encoding $S$. lycopersici tomatinase into pAN52-1 (Punt et al. 1987), under the control of the Aspergillus nidulans glyceraldehyde-3-phosphate dehydrogenase $(G P D)$ promoter. The $G P D$ promoter is expressed efficiently in C. fulvum (Roberts et al. 1989). The construction of pAN52-1/TOM resulted in a change in the DNA sequence encoding the first few amino acids of the signal peptide (from MVSSLF . . . to MDIPSLF . . .) (Osbourn et al. 1995). pAN52-1/TOM was introduced into a strain of each of $C$. fulvum races 4 and 5 by co-transformation with the plasmid pAN7-1, which contains the $h p h$ gene encoding hygromycin phosphotransferase (Punt et al. 1987). Control co-transformations were carried out with pAN52-1 (which does not contain the $S$. lycopersici tomatinase cDNA) and pAN7-1.

Preliminary analysis of hygromycin-resistant regenerants from these co-transformations identified six race 4 transformants and four race 5 transformants that expressed tomatinase activity. Three tomatinase-producing transformants per race were selected for further study (designated R4-T1, R4-T2 and R4-T3, and R5-T1, R5-T2, and R5-T3), along with three hygromycin-resistant transformants from control co-transformations of each race with pAN7-1 and pAN52-1 (see Materials and Methods) (designated R4-C1, R4-C2 and R4-C3, and R5-C1, R5-C2, and R5-C3).

Southern blot analysis of BamHI-digested genomic DNA indicated that the tomatinase-producing transformants of each race all contained DNA that hybridized strongly to the $S$. lycopersici cDNA probe. These transformants all appeared to have undergone simple integration events, with between two and four hybridizing bands each (consistent with one or two insertion sites respectively). R4-T2 gave a stronger hybridization signal than R4-T1 and R4-T3 when comparable DNA loadings were compared, indicating the presence of several copies of the tomatinase cDNA in this transformant. There was little variation in hybridization intensity among the tomatinase-producing race 5 transformants, which were all similar in intensity to R4-T1 and R4-T3. DNA of the race 5 wild-type $C$. fulvum strain and of the race 5 control transformants did not hybridize to the $S$. lycopersici cDNA probe. However, comparable amounts of DNA of the race 4 wild-type and control transformants did give weak hybridization after prolonged exposure, with all strains showing the same pattern.

In assays with glucose oxidase detection of $\alpha$-tomatinespecific glucose release, culture filtrates of the transformants R4-T1, R4-T2 and R4-T3, and R5-T1, R5-T2, and R5-T3 were all clearly able to hydrolyze D-glucose from $\alpha$-tomatine, while no activity was detected for the control transformants (Table 1). R4-T1 had lower tomatinase activity than R4-T2 and R4-T3, as assessed both by enzyme activity per microliter of concentrated culture filtrate and by specific activity (Table 1). The majority $(>70 \%)$ of the tomatinase activity in the transformants was extracellular (data not presented), indicating that the slight modification to the signal sequence during the construction of pAN52-1/TOM did not prevent secretion of tomatinase from C. fulvum. 
Moneymaker (Tables 3 and 4). Eleven days after inoculation, cotyledons of Moneymaker $C f 4$ that had been inoculated with the three race 4 control transformants $\mathrm{R} 4-\mathrm{C} 1, \mathrm{R} 4-\mathrm{C} 2$, and $\mathrm{R} 4-$ C3 either showed no signs of sporulation, or sparse sporulation (Table 3). Differences between the race 4 control strains in the level of sporulation were not significant $(P>5 \%)$. The effect of tomatinase on the ability of $C$. fulvum race 4 to sporulate on Moneymaker $C f 4$ was very highly significant $\left(\chi^{2}\right.$ $=50.38 ; 1 \mathrm{df} ; P<<0.1 \%)$. All cotyledons that had been inoculated with the race 4 tomatinase-producing transformants R4-T2 or R4-T3 showed sporulation at 11 days postinoculation, and in the majority of cases this was heavy (Table $3)$. The third tomatinase-producing transformant, R4-T1, clearly sporulated less than R4-T2 and R4-T3 $\left(\chi^{2}=20.6 ; 2 \mathrm{df}\right.$; $P<0.1 \%$ ), with $43 \%$ of cotyledons failing to show sporulation. However, unlike the control transformants, R4-T1 also gave heavy sporulation on some cotyledons.

A similar effect of tomatinase was observed for race 5 strains when inoculated onto $C f 5$ tomato seedlings, although in this interaction the control strains caused rather more disease than their race 4 counterparts, with more cotyledons showing sparse or heavy sporulation (Table 4). The tomatinase-producing race 5 transformants (R5-T1, R5-T2, and R5T3) all gave heavier sporulation than the race 5 control strains, and again the effect of tomatinase was highly significant $\left(\chi^{2}=\right.$ $8.71 ; 1 \mathrm{df} ; P<0.5 \%)$. There were no significant differences in sporulation levels between strains within either the race 5 control or tomatinase-producing groups.

There was no sign of sporulation even at 17 days after inoculation for the incompatible interactions between race 4 transformants and $C f 5$ tomato seedlings, or for the reciprocal interaction between race 5 transformants and $C f 4$ tomato seedlings, regardless of ability or inability to produce tomatinase. At this time after inoculation cotyledons that had been inoculated with virulent strains all showed heavy sporulation. Sporulation was not observed on mock-inoculated plants.

The experiment was repeated with similar results. In both experiments R4-T1 was less pathogenic than R4-T2 and R4T3.

Microscopic analysis of incompatible interactions between race 4 strains and Moneymaker $C f 5$ tomato seedlings.

For the race 4 strains all six parameters used to monitor fungal growth and seedling responses were strongly correlated

Table 3. Sporulation of Cladosporium fulvum race 4 transformants on seedlings of the susceptible tomato line Moneymaker $C f 4$

\begin{tabular}{|c|c|c|c|}
\hline \multirow[b]{2}{*}{ Inoculum } & \multicolumn{3}{|c|}{ Level of sporulation $(\% \text { cotyledons })^{\mathrm{z}}$} \\
\hline & 0 & + & ++ \\
\hline Mock & 100 & 0 & 0 \\
\hline R4-C1 a & 53 & 47 & 0 \\
\hline R4-C2 a & 88 & 12 & 0 \\
\hline R4-C3 a & 69 & 31 & 0 \\
\hline R4-T1 b & 43 & 43 & 14 \\
\hline R4-T2 c & 0 & 25 & 75 \\
\hline R4-T3 c & 0 & 33 & 67 \\
\hline
\end{tabular}

${ }^{\mathrm{z}}$ Sporulation on the upper surface of 20 cotyledons per treatment was scored 11 days after inoculation as follows: $0=$ no sporulation; + and $++=$ sparse and heavy sporulation, respectively. Strains of the same race marked with the same letter had sporulation levels which were not significantly different from one another $(P>5 \%)$. $(0.54<r<0.79 ; P<0.1 \%)$ (Table 5). Principal component analysis indicated that the first principal component accounted for $82 \%$ of the variation in pathogen development (lateral hyphal growth, number of hyphae, nature of branching, and depth of penetration) and $82 \%$ of the variation in seedling responses (cell rounding and cell death). The effects of tomatinase on both pathogen development and seedling response were very highly significant $(P<0.1 \%)$, while there were no significant differences between strains within the two groups, or between cotyledons $(P=5 \%)$ (Tables 5 and 6).

The race 4 control strains all showed very limited lateral hyphal growth and branching, and rarely penetrated beyond the first layer of the mesophyll (Table 5 and Fig. 1A). Typically, one or two mesophyll cells at the site of infection were enlarged and rounded, but the majority of these swollen cells did not accumulate trypan blue dye and hence were not scored as necrotic. The tomatinase-producing transformants R4-T1, R4-T2, and R4-T3 all showed substantially more growth in cotyledons of Moneymaker Cf5 than R4-C1, R4-C2, and R4C3 (Table 5 and Fig. 1B), with a mean increase in lateral hyphal growth of more than 6-fold, and with more extensive branching. Dichotomous branching was frequently observed (Table 5 and Fig. 1B). Hyphae generally penetrated the first two cell layers of the mesophyll and often extended beyond this, but never reached the vascular bundle. This increase in hyphal growth was accompanied by a substantial increase in the number of host cells showing rounding and necrosis. There was no sign of sporulation for any of the interactions between race 4 strains and Moneymaker Cf5 cotyledons (regardless of the presence or absence of the S. lycopersici tomatinase cDNA) even at 17 days after inoculation, while race 5 strains clearly sporulated on this host 11 days after inoculation (Table 4 and Fig. 1C).

\section{Microscopic analysis of incompatible interactions between race 5 strains and Moneymaker $\boldsymbol{C} \boldsymbol{f} 4$ tomato seedlings.}

The growth of the race 5 control strains R5-C1, R5-C2, and R5-C3 on cotyledons of Moneymaker Cf4 was much more extensive than that of the race 4 control strains on Moneymaker Cf5 (Table 5). Hyphae often penetrated beyond the second cell layer of the mesophyll, occasionally reaching the vascular tissue. There was extensive plant cell rounding and necrosis, in contrast to the interactions with the race 4 control strains. The tomatinase-producing strains

Table 4. Sporulation of Cladosporium fulvum race 5 transformants on seedlings of the susceptible tomato line Moneymaker $C f 5$

\begin{tabular}{|c|c|c|c|}
\hline \multirow[b]{2}{*}{ Inoculum } & \multicolumn{3}{|c|}{ Level of sporulation $(\% \text { cotyledons })^{\mathrm{z}}$} \\
\hline & 0 & + & ++ \\
\hline Mock & 100 & 0 & 0 \\
\hline $\mathrm{R} 5-\mathrm{C} 1 \mathrm{a}$ & 38 & 62 & 0 \\
\hline $\mathrm{R} 5-\mathrm{C} 2 \mathrm{a}$ & 47 & 47 & 6 \\
\hline $\mathrm{R} 5-\mathrm{C} 3 \mathrm{a}$ & 39 & 46 & 15 \\
\hline R5-T1 b & 25 & 44 & 31 \\
\hline R5-T2 b & 19 & 63 & 19 \\
\hline R5-T3 b & 13 & 69 & 19 \\
\hline
\end{tabular}

${ }^{\mathrm{z}}$ Sporulation on the upper surface of 20 cotyledons per treatment was scored 11 days after inoculation as follows: $0=$ no sporulation; + and $++=$ sparse and heavy sporulation, respectively. Strains of the same race marked with the same letter had sporulation levels which were not significantly different from one another $(P>5 \%)$. 
R5-T1, R5-T2, and R5-T3 all showed more advanced fungal development than the control strains, with increased lateral hyphal growth, numerous highly branched hyphae (many showing dichotomous branching), and frequent penetration to the vascular tissue.

All six parameters scored were correlated $(0.28<r<0.63)$ with $P<0.1 \%$ except for depth with rounding, branching, and hyphae $(1 \%>P>0.1 \%)$. Sixty percent of the variation in pathogen growth and $80 \%$ of the variation in seedling responses were accounted for by the first principal component (PC1). Analysis of variance (ANOVA) of PC1 indicated that the effects of tomatinase on fungal development were highly significant $(P<1 \%)$, with no significant differences between the different fungal strains within the two groups of transformants (Table 6). In contrast to race 4, there was no significant effect of tomatinase on seedling responses $(P>5 \%)$.

A similar analysis was carried out for the interaction between the race 5 strains and Moneymaker $C f 4$ with cotyledons that had been sampled at 11 days to test whether the differences between control and tomatinase-producing strains were any greater at this earlier stage of infection. In these experiments all four measurements of fungal growth were strongly correlated $(0.50<r<0.67 ; P<0.1 \%)$, while plant cell death was more weakly correlated and plant cell rounding was uncorrelated. The first principal component accounted for $70 \%$ of the pathogen variation and $64 \%$ of variation in seedling responses. ANOVA revealed a significant effect of tomatinase on pathogen development $(1 \%>P>0.1 \%)$, but not on seedling responses $(P>5 \%)$. There were no significant differences between strains.

\section{DISCUSSION}

Transformants of C. fulvum expressing S. lycopersici tomatinase showed increased sporulation on cotyledons of susceptible tomato lines and more extensive infection of seedlings of resistant tomato lines. These results imply that $\alpha$ tomatine contributes to the ability of tomato to restrict the growth of $C$. fulvum in both compatible and incompatible interactions.

It is well known that mature leaves of tomato contain $\alpha$ tomatine (e.g., Roddick 1974; Juvik and Stevens 1982; Juvik

Table 6. Analysis of variance of first principal component (PC1) for pathogen development and seedling response

\begin{tabular}{|c|c|c|c|c|c|}
\hline \multirow[b]{2}{*}{$\begin{array}{l}\text { Source of } \\
\text { variation }\end{array}$} & \multirow[b]{2}{*}{ df } & \multicolumn{2}{|c|}{ Pathogen } & \multicolumn{2}{|c|}{ Seedling } \\
\hline & & Variance & $\begin{array}{l}\text { Variance } \\
\text { ratio }\end{array}$ & Variance & $\begin{array}{l}\text { Variance } \\
\text { ratio }\end{array}$ \\
\hline \multicolumn{6}{|c|}{ Race 4 strains inoculated onto $C f 5$} \\
\hline Tomatinase & 1 & 139.2 & $55.5 * * * \mathrm{z}$ & z $\quad 50.1$ & $27.4 * * *$ \\
\hline Tomatinase $\times$ strain & 4 & 3.8 & $1.5 \mathrm{NS}$ & 1.1 & $0.6 \mathrm{NS}$ \\
\hline $\begin{array}{l}\text { Tomatinase } \times \text { strain } \\
\times \text { cotyledon }\end{array}$ & 14 & 2.5 & & 1.8 & \\
\hline Residual & 81 & 1.7 & & & \\
\hline \multicolumn{6}{|c|}{ Race 5 strains inoculated onto $C f 4$} \\
\hline Tomatinase & 1 & 39.8 & $15.4 * *$ & 8.3 & $3.4 \mathrm{NS}$ \\
\hline Tomatinase $\times$ strain & 4 & 4.3 & $1.6 \mathrm{NS}$ & 2.6 & $1.1 \mathrm{NS}$ \\
\hline $\begin{array}{l}\text { Tomatinase } \times \text { strain } \\
\times \text { cotyledon }\end{array}$ & 15 & 2.6 & & 2.4 & \\
\hline Residual & 60 & 1.7 & & & \\
\hline
\end{tabular}

Table 5. Microscopical analysis of the interaction between Cladosporium fulvum transformants and cotyledons of incompatible tomato lines 13 days after inoculation (means for each strain presented)

\begin{tabular}{|c|c|c|c|c|c|c|c|c|}
\hline Inoculum & $\begin{array}{l}\text { Infection sites } \\
\text { assessed (no.) }\end{array}$ & $\begin{array}{c}\text { Cotyledons } \\
\text { assessed (no.) }\end{array}$ & $\begin{array}{l}\text { Lateral hyphal } \\
\text { growth (EU) }\end{array}$ & $\begin{array}{c}\text { Hyphae } \\
(\text { no. })^{\mathrm{v}}\end{array}$ & $\begin{array}{c}\text { Nature of } \\
\text { branching }\end{array}$ & Depth $^{x}$ & $\begin{array}{l}\text { Plant cell } \\
\text { rounding }^{\mathrm{y}}\end{array}$ & $\begin{array}{c}\begin{array}{c}\text { Plant cell } \\
\text { death }^{\mathrm{z}}\end{array} \\
\end{array}$ \\
\hline \multicolumn{9}{|c|}{ Race 4 strains inoculated onto $C f 5$} \\
\hline $\mathrm{R} 4-\mathrm{C} 1$ & 16 & 3 & 1.8 & 0.8 & 0.0 & 0.4 & 0.9 & 0.3 \\
\hline $\mathrm{R} 4-\mathrm{C} 2$ & 13 & 4 & 1.0 & 0.3 & 0.2 & 0.5 & 0.9 & 0.2 \\
\hline $\mathrm{R} 4-\mathrm{C} 3$ & 15 & 3 & 1.5 & 0.6 & 0.5 & 0.9 & 1.5 & 0.6 \\
\hline Mean & & & 1.5 & 0.6 & 0.2 & 0.6 & 1.1 & 0.3 \\
\hline R4-T1 & 16 & 3 & 4.5 & 1.5 & 1.1 & 1.6 & 2.2 & 1.3 \\
\hline $\mathrm{R} 4-\mathrm{T} 2$ & 16 & 3 & 4.2 & 1.5 & 1.2 & 1.8 & 2.4 & 1.4 \\
\hline R4-T3 & 25 & 4 & 5.7 & 2.0 & 1.4 & 2.3 & 2.3 & 1.5 \\
\hline Mean & & & 4.9 & 1.7 & 1.3 & 1.9 & 2.3 & 1.4 \\
\hline \multicolumn{9}{|c|}{ Race 5 strains inoculated onto $C f 4$} \\
\hline R5-C1 & 12 & 3 & 9.3 & 1.4 & 0.7 & 2.5 & 1.8 & 1.0 \\
\hline $\mathrm{R} 5-\mathrm{C} 2$ & 18 & 4 & 9.2 & 2.2 & 1.2 & 2.6 & 2.1 & 1.6 \\
\hline $\mathrm{R} 5-\mathrm{C} 3$ & 8 & 4 & 8.1 & 2.0 & 0.9 & 2.6 & 2.3 & 1.5 \\
\hline Mean & & & 9.0 & 1.9 & 1.0 & 2.6 & 2.0 & 1.4 \\
\hline R5-T1 & 17 & 4 & 17.7 & 2.6 & 1.8 & 3.2 & 2.5 & 1.6 \\
\hline R5-T2 & 18 & 4 & 10.8 & 2.4 & 1.8 & 2.8 & 2.8 & 1.9 \\
\hline R5-T3 & 14 & 3 & 12.2 & 2.4 & 1.1 & 2.8 & 2.3 & 1.4 \\
\hline Mean & & & 13.6 & 2.5 & 1.6 & 2.9 & 2.6 & 1.7 \\
\hline
\end{tabular}

${ }^{u}$ Extent of lateral hyphal growth within the plant tissue was measured at individual infection sites with an eyepiece graticule and recorded as eyepiece units $(\mathrm{EU} ; 1 \mathrm{EU}=49.5 \mu \mathrm{M})$.

${ }^{\mathrm{v}}$ Number of hyphae emanating from a germ tube. Scores of $0,1,2$, and 3 indicate a single hypha, 2/3 hyphae, 3 to 6 hyphae, or $>6$ hyphae, respectively.

${ }^{\mathrm{w}}$ Presence of lateral and dichotomous branches. Scores of 0,1 , and 2 indicate no lateral branching, lateral branching present but not obviously dichotomous, or dichotomous branching evident, respectively.

${ }^{x}$ Depth of penetration of the hyphae into the cotyledon, assessed by scanning through the cotyledon and focussing on different cell layers. Scores of 0 , $1,2,3$, and 4 indicate that the hyphae have reached the stoma only (0), the first (1) and second (2) layers of the mesophyll, beyond the second layer but not yet at the vascular bundle (3), and the vascular bundle (4).

${ }^{\mathrm{y}}$ Plant responses were assessed by scoring cell rounding on a qualitative scale of 0 to 3

${ }^{\mathrm{z}}$ Plant responses were assessed by scoring trypan blue staining on a qualitative scale of 0 to 3 . 
et al. 1982), although the levels may vary markedly depending on environmental factors and physiologic state (Roddick 1974). However, the $\alpha$-tomatine content of tomato cotyledons has not been well documented. We determined that the levels of $\alpha$-tomatine in the foliar tissue of tomato plants harvested at the three-leaf stage were in the range 730 to $1,260 \mu \mathrm{g}$ per $\mathrm{g}$ of fresh weight, which compares well with other published values for L. esculentum, e.g., 591 to $1,070 \mu \mathrm{g}$ per $\mathrm{g}$ of fresh weight (Pegg and Woodward 1986), while cotyledons of 11day-old seedlings contained 260 to $579 \mu \mathrm{g}$ of $\alpha$-tomatine per $g$ of fresh weight. Thus the $\alpha$-tomatine levels of the cotyledons used in the infection studies were in the region of approximately 20 to $80 \%$ of that of 3-week-old foliage.

The growth of the $C$. fulvum race 4 and 5 wild-type strains on agar at $\mathrm{pH} 7$ was substantially inhibited by $100 \mu \mathrm{M} \alpha-$ tomatine (Table 2) and completely inhibited by $500 \mu \mathrm{M} \alpha$ tomatine. These results are in accordance with those of Dow and Callow (1978), who showed that similar levels of $\alpha$ tomatine inhibited $C$. fulvum germ tube extension at $\mathrm{pH} 7$. In plants, the effectiveness of $\alpha$-tomatine in restricting the growth of $C$. fulvum will depend on the concentrations that the saponin attains in the intercellular spaces and on other factors such as local $\mathrm{pH}$ and nutrient conditions (Dow and Callow 1978), parameters that are difficult to evaluate. For example, the $\mathrm{pH}$ in the intercellular fluid of uninfected tomato leaves is likely to be in the region of 5.3 to 6.4 (McCance and Drysdale 1975 ) and hence suboptimal for $\alpha$-tomatine toxicity. However, in infected plants the local $\mathrm{pH}$ may be modified by both fungal and host cell metabolic activity. Despite these uncertainties, the expression of $S$. lycopersici tomatinase in $C$. fulvum clearly enables the fungus to sporulate more extensively on seedlings of susceptible tomato lines (Table 3). This suggests that $\alpha$-tomatine is present in intercellular fluids of infected plants and does indeed exert an inhibitory effect on $C$. fulvum growth.

Expression of $S$. lycopersici tomatinase in $C$. fulvum race 4 clearly conferred increased ability to grow in the presence of $\alpha$-tomatine (Table 2). Although culture filtrates of R4-T1 contained less tomatinase activity than those of R4-T2 and R4-T3 (Table 1), R4-T1 showed $\alpha$-tomatine resistance intermediate between R4-T2 and R4-T3 in agar plate tests (Table 2 ). The reasons for this are unknown but may relate to differences in the abilities of the various strains to grow and to produce tomatinase under the different growth conditions used for the agar plate tests and liquid cultures. In contrast to race 4, expression of $S$. lycopersici tomatinase in $C$. fulvum race 5 did not result in increased resistance to $100 \mu \mathrm{M} \alpha$-tomatine in vitro, although it is possible that these strains may differ in their resistance at levels intermediate between 100 and 500 $\mu \mathrm{M}$ (not tested here). Both wild-type race 4 and 5 C. fulvum strains were unable to degrade $\alpha$-tomatine, although Southern blot analysis did reveal DNA sequences in the race 4 strain that hybridized to the $S$. lycopersici tomatinase cDNA probe. Tomatinase is a member of a family of enzymes that also includes a number of fungal and bacterial $\beta$-glucosyl hydrolases with no known role in saponin detoxification (Osbourn et al. 1995), and it may be that the hybridizing sequences in C. fulvum race 4 encode such an enzyme.

The microscopic observations of interactions between incompatible $C$. fulvum races and tomato lines on seedlings gave results that were very similar to those reported for ma- ture plants by Hammond-Kosack and Jones (1994). In both studies race 4 hyphae rarely penetrated more than two cell layers of $C f 5$ plants, and gave rise to only limited rounding of mesophyll cells and very little plant cell death. In contrast, growth of race 5 on $C f 4$ plants was much more extensive, and there was considerable plant cell rounding and necrosis at the later stages of infection. The effects of S. lycopersici tomatinase expression on fungal development in these interactions were striking, particularly for race 4 . This suggests that release of $\alpha$-tomatine from damaged plant cells may contribute to the killing or containment of the invading fungus during incompatible $C$. fulvum/tomato interactions, as suggested by Dow and Callow (1978).

These experiments are supportive of a role for $\alpha$-tomatine in inhibiting the growth of $C$. fulvum in interactions with both susceptible and resistant tomato seedlings; however, they do not provide conclusive evidence of this. It is possible, for instance, that the heterologous expression of S. lycopersici tomatinase may have some other unforeseen effects on $C$. fulvum/tomato interactions in addition to conferring $\alpha$-tomatinedetoxifying activity. A direct genetic test of the importance of this saponin in protection of tomato plants against attack by $C$. fulvum and other pathogens will be afforded by the isolation of mutants of tomato that lack $\alpha$-tomatine. This will be the subject of future investigations.

\section{MATERIAL AND METHODS}

\section{Fungal isolates and culture conditions.}

The C. fulvum (syn. Fulvia fulva) race 4 and race 5 strains used in this study were obtained from M. Gerlagh, Institut voor Plantenziektenkundig Onderzoek, Wageningen (strain numbers 10879 and 30381, respectively). Strains were routinely maintained on V8 agar containing $50 \mu \mathrm{g}$ of streptomycin sulfate per $\mathrm{ml}$ at $25^{\circ} \mathrm{C}$ (16 h day), as described by Harling et al. (1988). Spore suspensions in $10 \%$ glycerol were prepared from 2-week-old colonies.

\section{DNA manipulations.}

DNA manipulations were carried out by standard techniques (Sambrook et al. 1989). Fungal genomic DNA was prepared as described in Raeder and Broda (1985) from mycelium grown in $\mathrm{B} 5$ liquid medium for 7 to 10 days $\left(25^{\circ} \mathrm{C}\right.$ in the dark, with shaking at $120 \mathrm{rpm}$; Controlled Environment Incubator Shaker, New Brunswick Scientific, Edison, NJ) (Van den Ackerveken et al. 1992). The presence of the $S$. lycopersici tomatinase DNA in the transformants was confirmed by Southern blot analysis with the $2.5-\mathrm{kb}$ HindIII restriction fragment of pCTOM6 as a probe with hybridization at $65^{\circ} \mathrm{C}$, and washes of $6 \times \mathrm{SSC}(1 \times \mathrm{SSC}$ is $0.15 \mathrm{M} \mathrm{NaCl}$ plus $0.015 \mathrm{M}$ sodium citrate), $0.1 \%$ sodium dodecyl sulfate (SDS), and $2 \times$ SSC, $0.1 \%$ SDS (also at $65^{\circ} \mathrm{C}$ ).

\section{Vector construction.}

Previously, a 2.5-kb DNA HindIII restriction fragment encoding $S$. lycopersici tomatinase was isolated from the cDNA clone pCTOM6 (Osbourn et al. 1995; GenBank accession number U35462), and after infilling was ligated into the SmaI site of the expression vector pIAT, which contains the Neurospora crassa isocitrate lyase promoter (kindly provided by I. Connerton, Institute of Food Research, Reading, UK). For 
expression in $C$. fulvum the tomatinase cDNA was recovered from the pIAT construct as an NcoI-HindIII fragment and ligated into NcoI-HindIII-digested pAN52-1 (Punt et al. 1987) under the control of the Aspergillus nidulans GPD promoter. The DNA sequence of the resulting plasmid pAN52-1/TOM was determined in the region of the $5^{\prime}$ end of the tomatinase coding sequence and confirmed to be $5^{\prime}$ - ATG GAT ATT CCC AGC - 3', where the authentic tomatinase sequence begins at AGC (underlined), corresponding to nucleotide position 10 of the full coding sequence. This results in a change in the $\mathrm{N}$-terminal sequence of the first few amino acids of the signal peptide from MVSSLF to MDIPSLF.

\section{Tomatinase assays.}

Five-milliliter or 50-ml batches of B5 liquid medium (De Wit and Flach 1979) were inoculated with a spore suspension of $6 \times 10^{4}$ spores per $\mathrm{ml}$, and cultures were grown for between 7 and 21 days in the dark at $25^{\circ} \mathrm{C}$ with shaking $(120 \mathrm{rpm}$; Controlled Environment Incubator Shaker, New Brunswick Scientific). After filtering through Miracloth (Calbiochem, La Jolla, CA) proteins were precipitated from culture filtrates by addition of ammonium sulfate to a final concentration of $80 \%$, and pelleted by centrifugation. Pellets were resuspended in sterile water before dialysis overnight, and all preparations were adjusted to a final volume of $1.5 \mathrm{ml}$ with sterile water. Tomatinase activity was routinely determined by measurement of $\alpha$-tomatine-specific glucose release by the glucose oxidase assay as described in Osbourn et al. (1995). Protein concentrations were determined by the BioRad Protein Assay with lysozyme as a standard.

Tomatinase assays for TLC analysis were carried out as described in Osbourn et al. (1995), and incubations with $S$. lycopersici tomatinase were included for comparison. Incubation mixtures were vacuum dried and resuspended in $20 \mu \mathrm{l}$ of methanol prior to separation on a Silica Gel $600.25 \mathrm{~mm}$ TLC plate (Merck AG, Darmstadt, Germany). The plates were developed with acetic acid:ethyl acetate:methanol:water (10: 30:20:1), and spots were visualized by spraying with a solution of $p$-anisaldehyde/sulfuric acid/acetic acid (1:1:48) and baking at $130^{\circ} \mathrm{C}$ for 5 to $30 \mathrm{~min}$.

All experiments were done at least twice.

\section{Effects of $\alpha$-tomatine on fungal growth.}

Fifty to 500 spores per petri dish were plated onto MCD agar $\left(0.5 \mathrm{~g} \mathrm{l}^{-1} \mathrm{NaNO}_{3}, 0.5 \mathrm{~g} \mathrm{l}^{-1} \mathrm{KCl}, 0.5 \mathrm{gl}^{-1} \mathrm{MgSO}_{4}, 1 \mathrm{~g} \mathrm{l}^{-1}\right.$ $\mathrm{KH}_{2} \mathrm{PO}_{4}, 15 \mathrm{~g} \mathrm{l}^{-1}$ sucrose, $30 \mathrm{~m} \mathrm{~g} \mathrm{l}^{-1} \mathrm{FeSO}_{4}, \mathrm{pH} \mathrm{7}$, solidified with $2 \%$ agar) containing $50 \mu \mathrm{g}$ of streptomycin per $\mathrm{ml}$ in the presence or absence of $\alpha$-tomatine. $\alpha$-Tomatine stock solutions $(10 \mathrm{mM})$ were prepared in $100 \mathrm{mM}$ sodium acetate buffer, $\mathrm{pH}$ 4.5. Control plates received buffer alone. The diameters of 20 colonies per treatment were measured by a dissection microscope with an eyepiece graticule at a magnification of $\times 36$.

\section{Generation of $C$. fulvum transformants expressing $S$. lycopersici tomatinase.}

Protoplasts were prepared according to Harling et al. (1988), and transformations were carried out as described in Oliver et al. (1987) with the modifications of Van den Ackerveken et al. (1992). Either pAN52-1/TOM (containing the $S$. lycopersici tomatinase cDNA) or pAN52-1 (a control plasmid lacking the tomatinase cDNA) was introduced into $C$. fulvum races 4 and 5 by co-transformation with pAN7-1, which contains the gene encoding hygromycin phosphotransferase (Punt et al. 1987), with selection at $100 \mu \mathrm{g}$ of hygromycin B per ml. Thirty hygromycin-resistant transformants from each cotransformation involving pAN52-1/TOM were isolated and purified by two successive rounds of single-spore isolation on V8 medium containing $100 \mu \mathrm{g}$ of hygromycin B per ml. Three hygromycin-resistant transformants from the control cotransformations (using pAN52-1) were similarly purified. All transformants were maintained on V8 medium containing 100 $\mu \mathrm{g}$ of hygromycin B per $\mathrm{ml}$, and spore suspensions were frozen in $10 \%$ glycerol for long-term storage.

\section{Seedling infection studies.}

Seeds of near-isogenic lines of the tomato (Lycopersicon esculentum) cultivar Moneymaker that were homozygous for the $C f 4$ or $C f 5 C$. fulvum disease resistance genes (from M. Gerlagh, Institut voor Plantenziektenkundig Onderzoek, Wageningen) were sown in 7.62-cm pots with three seeds per pot, and after 11 days the strongest seedling in each pot was retained and inoculated with $C$. fulvum by immersing the
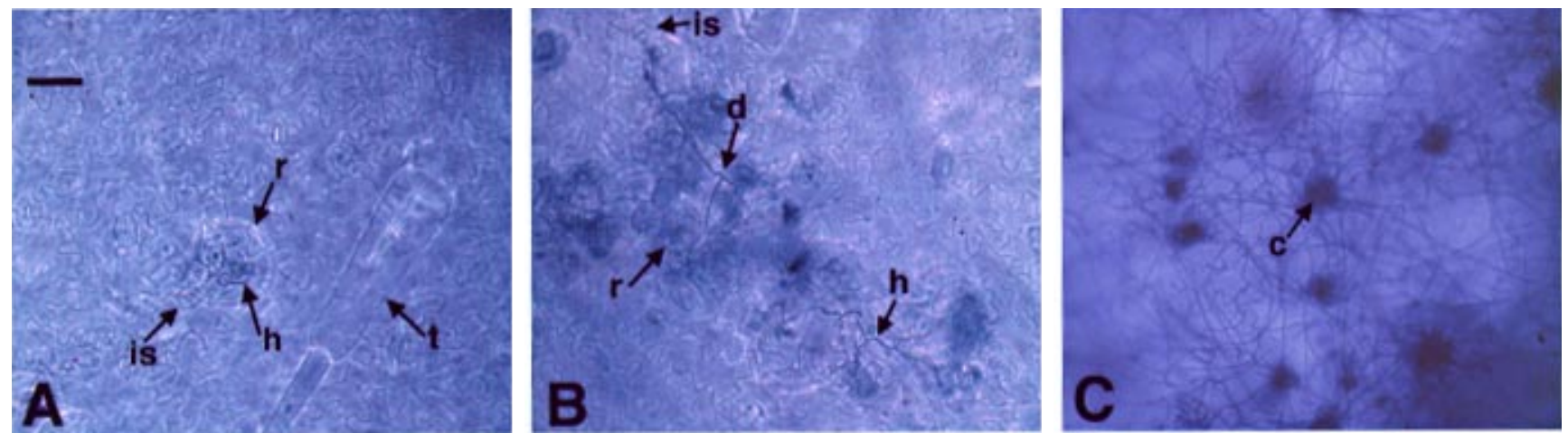

Fig. 1. Microscopic analysis of cotyledons of Moneymaker Cf5 infected with Cladosporium fulvum (13 days after inoculation). A, A control race 4 strain (R4-C3) showing limited hyphal growth; a rounded host mesophyll cell is visible. B, A tomatinase-producing race 4 strain (R4-T3) showing dichotomous branching and considerable hyphal growth within the plant tissue. Extensive host cell rounding and necrosis (the latter in dicated by blue staining) are also evident. C, Sporulation of the compatible race 5 wild type on Moneymaker Cf5. Abbreviations: h, hyphae; is, infection site; r, plant cell rounding; $t$, trichome; d, dichotomous branch; c, conidiophore. Intact cotyledons were stained with lactophenol-trypan blue. Scale bar is equivalent to $20 \mu \mathrm{M}$ and applies to all three panels. 
cotyledons in a suspension of $5 \times 10^{5}$ conidia per $\mathrm{ml}$ in sterile, distilled water as described in Hammond-Kosack et al. (1994). Controls that had been mock inoculated with sterile, distilled water were also included. Inoculated seedlings were allowed to dry for several hours and were then randomized in plastic propagators and maintained in a growth cabinet with a 16-h day (illumination provided by $100 \mu \mathrm{E} \cdot \mathrm{s}^{-1} \cdot \mathrm{m}^{-2}$ broad spectrum $400 \mathrm{~W}$ fluorescent metal halide Kolar Arc lamps) and with a temperature of $25^{\circ} \mathrm{C}$ day, $22^{\circ} \mathrm{C}$ night, and 60 to $70 \%$ humidity. Propagators were kept closed for the first 3 days and thereafter the lids were removed during the day and closed at night. Seedlings were scored from 7 to 17 days after inoculation by assessing the degree of sporulation on the cotyledons.

Microscopic analysis was also carried out to assess fungal growth and host response, following an approach similar to that of Hammond-Kosack and Jones (1994). Four cotyledons per host genotype/fungal strain combination were sampled 7 , 11,13 , and 17 days after inoculation. Cotyledons were boiled for $1 \mathrm{~min}$ in trypan blue/lactophenol $(10 \mathrm{ml}$ of lactic acid, $10 \mathrm{~g}$ of phenol, $10 \mathrm{ml}$ of glycerol, $10 \mathrm{ml}$ of water, $10 \mathrm{mg}$ of trypan blue, mixed 1:1 with ethanol), and destained for 2 days in several changes of chloral hydrate $(2.5 \mathrm{~g} / \mathrm{ml})$ before mounting abaxial side uppermost in chloral hydrate. The stained tissue was viewed with a Zeiss "Axioskop" microscope under bright-field illumination at $\times 20$ magnification, and photographs were taken with Kodak Ektachrome 160 Tungsten film. Pathogen development and host responses were scored for a total of 8 to 25 infection sites on either 3 or 4 cotyledons per treatment.

\section{Determination of $\alpha$-tomatine content of plant material.}

Seedlings were grown under the same conditions as for infection studies, and three batches of 8 cotyledons were harvested for each tomato line when the seedlings were 11 days old. Plants were also grown under identical conditions and harvested at the three-leaf stage (approximately 3 weeks old) by cutting the stem off just above the cotyledons. Extracts were prepared from three plants of each of Moneymaker $C f 4$ and $C f 5$.

$\alpha$-Tomatine was extracted from tomato cotyledons and leaves as described by Keukens et al. (1994). The plant tissue was weighed, and then ground in methanol with a pestle and mortar. The extract was centrifuged at $15,000 \times g$ for $10 \mathrm{~min}$, the supernatant decanted, and the pellet re-extracted with methanol. After a second centrifugation step the supernatants were combined, and adjusted to $40 \%$ methanol. The extracts were then applied to Sep-Pak C18 cartridges (Waters, Milford, MA) that had been preconditioned with $10 \mathrm{ml}$ of methanol followed by $10 \mathrm{ml}$ of distilled water. After addition of the sample, the column was washed with 10 -ml volumes of $40 \%$ methanol. $\alpha$-Tomatine was then eluted with $25 \mathrm{ml}$ of $80 \%$ methanol, evaporated to dryness in a Spin Vac, and redissolved in $1 \mathrm{ml}$ of methanol before quantification by the hemolysis procedure of Juvik and Stevens (1982).

\section{Data analysis.}

Data on in vitro growth of C. fulvum (Table 2) was subjected to ANOVA of log-transformed data, the residual factor being plates of the same strain. For race 4 , the variance ratio relating to the interaction between strains and $\alpha$-tomatine was highly significant $(P<0.1 \%)$, and hence strains were com- pared by Fisher's protected least significant difference. For race 5 , the strain $\times \alpha$-tomatine variance ratio was not significant $(P>5 \%)$, and so differences between strains were not examined further.

The sporulation of $C$. fulvum in compatible interactions (Table 3 ) was analyzed by generalized linear modeling (GLM) of the numbers of cotyledons showing the three classes of sporulation (Everitt 1977; Genstat 5 Committee 1993). Sporulation was fitted as a linear variable, with three equally spaced levels, as shown in Table 3. Interactions between sporulation and the class of transformant (tomatinaseproducing or not) were analyzed. When these were shown to be significant, interactions between sporulation and strains within tomatinase-producing classes were examined by GLM.

Principal components analyses were carried out on matrices of correlations between four variables describing pathogen development in incompatible interactions, and on two variables describing plant responses (Table 5). For both pathogen and plant data, for both races 4 and 5, the first principal component (PC1) accounted for the great majority of the variation, so the variables analyzed could be considered as all reflecting a single underlying variable, described by PC1. ANOVA was therefore carried out on PC1 scores. The effects of tomatinase and of strains within tomatinase-producing groups were analyzed, the residual factor being replicate cotyledons infected with strain. Variation between cotyledons was compared with variation between germlings on a cotyledon.

All data analysis was done with the Genstat 5 package, version 3.2 (Numerical Algorithms Group, Oxford).

\section{ACKNOWLEDGMENTS}

The Sainsbury Laboratory is supported by the Gatsby Charitable Foundation. We thank Kim Hammond-Kosack and Max Dow for advice during the experimental work, and also for commenting on the manuscript.

\section{LITERATURE CITED}

Arneson, P. A., and Durbin, R. D. 1967. Hydrolysis of tomatine by Septoria lycopersici: A detoxification mechanism. Phytopathology 57: 1358-1360.

Arneson, P. A., and Durbin, R. D. 1968a. The sensitivity of fungi to $\alpha-$ tomatine. Phytopathology 58:536-537.

Arneson, P. A., and Durbin, R. D. 1968b. Studies on the mode of action of tomatine as a fungitoxic agent. Plant Physiol. 43:683-686.

Batista, U. G., and Higgins, V. J. 1991. Accumulation of phytoalexins in the compatible interaction between Cladosporium fulvum and tomato in relation to colonization. Can. J. Bot. 69:822-830.

Bowyer, P., Clarke, B. R., Lunness, P., Daniels, M. J., and Osbourn, A. E. 1995. Host range of a plant pathogenic fungus determined by a saponin detoxifying enzyme. Science 267:371-374.

De Wit, P. J. G. M. 1977. A light and scanning-electron microscopic study of infection of tomato plants by avirulent and virulent races of Cladosporium fulvum. Neth. J. Plant Pathol. 83:109-122.

De Wit, P. J. G. M. 1992. Molecular characterization of gene-for- gene systems in plant-fungus interactions and the application of avirulence genes in control of plant pathogens. Annu. Rev. Phytopathol. 30:391418.

De Wit, P. J. G. M., and Flach, W. 1979. Differential accumulation of phytoalexins in tomato leaves but not in fruits after inoculation with virulent and avirulent races of Cladosporium fulvum. Physiol. Mol. Plant Pathol. 15:257-267.

De Wit, P. J. G. M., and Kodde, E. 1981. Induction of polyacetylenic phytoalexins in Lycopersicon esculentum after inoculation with Cladosporium fulvum (syn. Fulvia fulva). Physiol. Plant Pathol. 18:143148 . 
Défago, G., and Kern, H. 1983. Induction of Fusarium solani mutants insensitive to tomatine, their pathogenicity and aggressiveness to tomato fruits and pea plants. Physiol. Mol. Plant Pathol. 22:29-37.

Défago, G., Kern, H., and Sedlar, L. 1983. Genetic analysis of tomatine insensitivity, sterol content and pathogenicity for green tomato fruits in mutants of Fusarium solani. Physiol. Mol. Plant Pathol. 22:39-43.

Dow, J. M., and Callow, J. A. 1978. A possible role for $\alpha$-tomatine in the varietal-specific resistance of tomato to Cladosporium fulvum. Phytopathol. Z. 92:211-216.

Everitt, B. S. 1997. The Analysis of Contingency Tables. Chapman \& Hall, London.

Genstat 5 Committee. 1993. Genstat 5 Release 3 Reference Manual. Oxford University Press, Oxford.

Hammond-Kosack, K. E., and Jones, J. D. G. 1994. Incomplete dominance of tomato $C f$ genes for resistance to Cladosporium fulvum. Mol. Plant-Microbe Interact. 7:58-70.

Hammond-Kosack, K. E., Jones, D. A., and Jones, J. D. G. 1994. Identification of two genes required in tomato for full $C f$-9-dependent resistance to Cladosporium fulvum. Plant Cell 6:361-374.

Hammond-Kosack, K. E., Silverman, P., Raskin, I., and Jones, J. D. G. 1996. Race-specific elicitors of Cladosporium fulvum induce changes in cell morphology and the synthesis of ethylene and salicylic acid in tomato plants carrying the corresponding $C f$ disease resistance gene. Plant Physiol. 110:1381-1394.

Harling, R., Kenyon, L., Lewis, B. G., Oliver, R. P., Turner, J. G., and Coddington, A. 1988. Conditions for efficient isolation and regeneration of protoplasts from Fulvia fulva. J. Phytopathol. 122:143-146.

Juvik, J. A., and Stevens, M. A. 1982. Inheritance of foliar $\alpha$-tomatine content in tomatoes. J. Am. Hortic. Sci. 107:1061-1065.

Juvik, J. A., Stevens, M. A., and Rick, C. M. 1982. Survey of the genus Lycopersicon for variability in $\alpha$-tomatine content. Hortic. Sci. 17: 764-766.

Keukens, E. A. J., de Vrije, T., van den Boom, C., de Waard, P., Plasmna, H. H., Thiel, F., Chupin, V., Jongen, W. M. F., and de Kruijff, B. 1995. Molecular basis of glycoalkaloid induced membrane disruption. Biochim. Biophys. Acta 1240:216-228.

Keukens, E. A. J., Hop, M. E. C. M., and Jongen, W. M. F. 1994. Rapid high-performance liquid chromatographic method for the quantification of $\alpha$-tomatine in tomato. J. Agric. Food Chem. 42:2475-2477.

Lairini, K., Perez-Espinosa, A., Pineda, M., and Ruiz-Rubio, M. 1996. Purification and characterization of tomatinase from Fusarium oxysporum. f. sp. lycopersici. Appl. Environ. Microbiol. 62:1604-1609.

Lazarovitz, G., and Higgins, V. J. 1976. Ultrastructure of susceptible, resistant and immune reactions of tomato to races of Cladosporium fulvum. Can. J. Bot. 54: 235-249.

May, M. J., Hammond-Kosack, K. E., and Jones, J. D. G. 1996. Involvement of reactive oxygen species, glutathione metabolism, and lipid peroxidation in the $C f$-gene-dependent defense response of tomato cotyledons induced by race-specific elicitors of Cladosporium fulvum. Plant Physiol. 110:1367-1379.

McCance, D. J., and Drysdale, R. B. 1975. Production of tomatine and rishitin in tomato plants inoculated with Fusarium oxysporum f. sp. lycopersici. Physiol. Plant Pathol. 7:221-230.

Oliver, R. P., Roberts, I. N., Harling, R., Kenyon, L., Punt, P. J., Dingemanse, M. A., and Van den Hondel, C. A. M. J. J. 1987. Transformation of Fulvia fulva, a pathogen of tomato, to hygromycin B resistance. Curr. Genet. 12:231-233.

Osbourn, A., Bowyer, P., Lunness, P., Clarke, B., and Daniels, M. 1995.
Fungal pathogens of oat roots and tomato leaves employ closely related enzymes to detoxify host plant saponins. Mol. Plant-Microbe Interact. 8:971-978.

Osbourn, A. E. 1996a. Saponins and plant defence - A soap story. Trends Plant Sci. 1:4-9.

Osbourn, A. E. 1996b. Preformed antimicrobial compounds and plant defense against fungal attack. Plant Cell 8:1821-1831.

Pegg, G. F., and Woodward, S. 1986. Synthesis and metabolism of $\alpha-$ tomatine in tomato isolines in relation to resistance to Verticillium albo-atrum. Physiol. Mol. Plant Pathol. 28:187-201.

Punt, P. J., Oliver, R. P., Dingemanse, M. A., Pouwels, P. H., and van den Hondel, C. A. M. J. J. 1987. Transformation of Aspergillus based on the hygromycin B resistance marker from Escherichia coli. Gene 56:117-124.

Raeder, U., and Broda, P. 1985. Rapid preparation of the DNA from filamentous fungi. Lett. Appl. Microbiol. 1:17-20.

Roberts, I. N., Oliver, R. P., Punt, P. J., and van den Hondel, C. A. M. J. J. 1989. Expression of the Escherichia coli $\beta$-glucuronidase gene in industrial and phytopathogenic filamentous fungi Curr. Genet. 15: $177-180$.

Roddick, J. G. 1974. The steroidal glycoalkaloid $\alpha$-tomatine. Phytochemistry 13:9-25.

Roddick, J. G., and Drysdale, R. B. 1984. Destabilization of liposome membranes by the steroidal glycoalkaloid $\alpha$-tomatine. Phytochemistry 23:543-547.

Sambrook, J., Fritsch, E. F., and Maniatis, T. A. 1989. Molecular Cloning: A Laboratory Manual. 2nd ed. Cold Spring Harbor Laboratory, Cold Spring Harbor, NY.

Sandrock, R. W., DellaPenna, D., and VanEtten, H. D. 1995. Purification and characterization of $\beta_{2}$-tomatinase, an enzyme involved in the degradation of $\alpha$-tomatine and isolation of the gene encoding $\beta_{2}$ tomatinase from Septoria lycopersici. Mol. Plant-Microbe Interact. 8: 960-970.

Schlösser, E. 1972. Sterol dependent membranelytic action of saponins. Phytopathol. Z. 74:91-94.

Schlösser, E. 1975. Role of saponins in antifungal resistance. III. Tomatine dependent development of fruit rot organisms of tomato fruits. Z. Pflanzenkrankh. Pflanzenschutz 82:476-484.

Schönbeck, F., and Schlösser, E. 1976. Preformed substances as potential protectants. Pages 653-678 in: Physiological Plant Pathology. R. Heitefuss and P. H. Williams, eds. Springer-Verlag, Berlin,

Schulz, G., and Sander, H. 1957. Über cholesterin-Tomatid. Eine neue Molekülverbinding zur anlyse und preparativen Gewinnung von Steroiden. Hoppe-Seyler's Z. Physiol. Chem. 308:122-126.

Steel, C. S., and Drysdale, R. B. 1988. Electrolyte leakage from plant and fungal tissues and disruption of liposome membranes by $\alpha$ tomatine. Phytochemistry 27:1025-1030.

Suleman, P., Tohamy, A. M., Saleh, A. A., Madkour, M. A., and Straney, D. C. 1996. Variation in sensitivity to tomatine and rishitin among isolates of Fusarium oxysporum f. sp. lycopersici, and strains not pathogenic on tomato. Physiol. Mol. Plant Pathol. 48:131-144.

Van den Ackerveken, G. F. J. M., Van Kan, J. A. L., and De Wit, P. J. G M. 1992. Molecular analysis of the avirulence gene $a v r 9$ of the fungal tomato pathogen Cladosporium fulvum fully supports the gene for gene hypothesis. Plant J. 2:359-366.

Van Dijkman, A., and Kaars-Sijpesteijn, A. K. 1971. A biochemical mechanism for the gene-for-gene resistance of tomato to Cladosporium fulvum. Neth. J. Plant Pathol. 77:14-24. 